\title{
Evaluation of the maxillary premolar roots dissociation using radiographic holders with conventional and digital radiography
}

\section{Marcia Regina Ramalho da Silva Bardauil(a) \\ Cacio de Moura Netto(b) \\ Abílio Albuquerque Maranhão de Moura ${ }^{(b)}$}

(a) PhD, Department of Endodontics, Dental School, University Paulista, São Paulo, SP, Brazil.

(b) PhD, Department of Endodontics, Dental School, University of São Paulo, São Paulo, SP, Brazil.

\section{Corresponding author:}

Marcia Regina Ramalho da Silva Bardauil Universidade Paulista

Rua Helena, 218 - cj 212

São Paulo - SP - Brazil

CEP: 04552-050

E-mail:marciarebardaendo@uol.com.br

Received for publication on Jan 11, 2010 Accepted for publication on May 31, 2010

\begin{abstract}
This in vivo study evaluated the dissociation quality of maxillary premolar roots combining variations of vertical and horizontal angulations by using X-ray holders (Rinn - XCP), and made a comparison between two types of intraoral radiography systems - conventional film (Kodak Insight, Rochester, USA) and digital radiography (Kodak RVG 6100, Kodak, Rochester, USA). The study sample was comprised of 20 patients with a total of 20 maxillary premolars that were radiographed, using the paralleling angle technique (GP), with a $20^{\circ}$ variation of the horizontal angle $(\mathrm{GM})$ and $25^{\circ}$ variation of the horizontal angle combined with $15^{\circ}$ vertical angle (GMV). Each image was independently analyzed by two experienced examiners. These examiners assigned a score to the diagnostic capability of root dissociation and the measurement of the distance between the apexes. Statistical data was derived using the Wilcoxon Signed Rank test, Friedman and T test. The means of the measured distances between buccal and lingual root apexes were greater for the GMV, which ranged from $2.3 \mathrm{~mm}$ to $3.3 \mathrm{~mm}$. A statistically significant difference was found between GM and GMV when compared to GP with $\mathrm{p}<0.01$. An established best diagnostic dissociation roots image was found in the GMV. These results support the use of the anterior X-ray holders which offer a better combined deviation (GMV) to dissociate maxillary premolar roots in both radiography systems.
\end{abstract}

Descriptors: Radiography, dental; Radiography, dental, digital; Endodontics; Radiographic image enhancement.

\section{Introduction}

The complexity of the root canal system demands extra care from the endodontist in the morphological analysis when treating a tooth, requiring information related to the number and shape of roots and canals, in order to plan and carry out a satisfactory endodontic treatment. Radiographic investigations are routinely used as part of the assessment of new endodontic treatment and these radiographic investigations provide tangible benefits to the endodontist when planning a treatment. ${ }^{1,2,3}$

The parallelism radiography technique is commonly used as an initial diagnostic tool, because it provides valuable information of a vari- 
ety of anatomic conditions throughout the coronal - radicular structures. The parallelism radiography technique has the advantage of a standardized procedure that can be used during the entire endodontic treatment. ${ }^{4,5}$

Although, in certain tooth groups, several different cone angulations are necessary in order to be able to overcome the superimposition of roots which reflect the shape of the tooth in third dimension. For example, the maxillary premolars, according to literature, may have two roots and two canals $\left(70 \%{ }^{6,7}\right.$ to $98 \%{ }^{8}$ ) and may nearly always have the appearance of a single root. The roots of maxillary premolars are often superimposed in the buccolingual direction, which is the same direction of the X-ray beam.

Previously, in such cases, a variation of 20 degrees mesially in a horizontal angulation has been suggested in order to dissociate the superimposed roots. ${ }^{9}$ In many cases, the deviation overcomes the superimposition, but by contrast, can bring the disadvantage of producing geometric distortions by elongating or foreshortening the apparent root length of the premolars. ${ }^{4}$

In endodontic clinics, the lowest possible number of radiographies can minimize the amount of radiation exposure for both the professional and the patient, following the principle of ALARA (As Low As Reasonably Achievable). ${ }^{1}$

The intraoral digital radiographic system has acquired great significance as a diagnostic tool, because of the improvement of sensor spatial resolution and the reduction of exposure time by up to $90 \%$ for images similar to those of radiographic films. ${ }^{10,11,12,13,14}$

In relation to endodontics, many studies have analyzed and reported the diagnostic capabilities of digital images, , $^{15,16,17,18,19,20}$ for endodontic procedures $^{12,13,21}$ and follow ups of endodontic treatment, ${ }^{17,21}$ which clearly demonstrates the efficacy and safety of the digital system.

It is, therefore, important that all intraoral dental exposures are taken with the corresponding holders and the paralleling technique. ${ }^{22}$ However, some clinicians have reported their difficulty to properly make deviation, sometimes making additional radi- ographies.

In this context, the present in vivo study aimed to use radiographic holders to correctly place the film or sensor in the oral cavity in order to evaluate the dissociation of the maxillary premolars roots.

\section{Material and Methods}

After the approval of an Ethics Committee, twenty patients were randomly selected from patients screened for Endodontic treatment at the Clinics of the School of Dentistry, Paulista University, and invited to participate in this study. Only patients that had at least one maxillary premolar, left or right, with two roots and without periapical lesion, indicated for endodontic treatment were considered for participation in the study. If the patient did not fulfill these conditions or the patient's tooth presented anatomic complications, like severe curvatures, apical resorptions or differences of root length greater than $5 \mathrm{~mm}$, the candidate would be treated but excluded from the study. All patients were informed about the study, about its risks and benefits, and signed an agreement concerning their participation.

Six images were made of each patient, 3 conventional (CR) and 3 digital radiographs (DR) in three periapical radiographic techniques. The three periapical radiographic techniques were: Parallelism (GP), Parallelism with a variation of $20^{\circ}$ horizontal angulation mesially (GM) and Parallelism with a variation of the mesio-vertical angle of $25^{\circ}$ and $15^{\circ}$ respectively (GMV). A total of 120 images were obtained, divided into 6 groups of 20 images, to represent the three techniques associated with the two systems (CR and DR) (table 1).

All periapical images (CR and DR) were exposed using conventional X-ray equipment, $70 \mathrm{kV}, 8 \mathrm{~mA}$ (Trophy Radiologie, Vincennes, France) with a focal distance of $30 \mathrm{~cm}$. Kodak Insight film (Eastman Kodak Co., Rochester, USA) was used with an exposure time of $0.32 \mathrm{~s}$ and RVG 6100 (Kodak, Rochester, USA), sensor \#1, with an exposure time of $0.18 \mathrm{~s}$.

All radiographs, conventional and DR, were taken using a Rinn-XCP support (DentsplyRinn, Elgin, IL, USA). The posterior tooth film holder was used for the GP. The anterior tooth film holder indicates 
the angulations of $15^{\circ}$ vertical and $25^{\circ}$ horizontal for the GMV. Another guide ring was confectioned and placed $20^{\circ}$ to the posterior ring, thereby reproducing $20^{\circ}$ mesially. The bite block was always positioned on the patients' first premolar. In order to standardize and customize X-ray projections, an impression of the patient's bite was taken with heavy body silicone (Zetaplus - ZhermackSpA, Badia Polesine RO, Italy) in order to maintain the support in the same position for all 3 techniques.

The CR images were processed with an automatic Periomat device (Dürr Dental, Bietigheim-Bissingen, Germany) and DR images were stored in TIFF format and each image was identified (only in file name) by patient and the corresponding group technique angulation, GP, GM or GMV.

All images were evaluated by two expert examiners, a dental radiologist and an endodontist. Observations were individually made by the examiners, in a dark room during two different sessions (first one for conventional and the other for digital radiographs) with 3 weeks between the two intervals, in order to avoid the tendency of remembering the measurement from the first session and allowing that measurement to influence the same case during the second session. CR images were evaluated using a light box (Rinn Co. Abbott Drive Elgin,
IL, USA) and a magnifier lens (2 X). Measurements were made with a flexible and calibrated transparent acrylic ruler, graduated in millimeters and half millimeters (Trident Desetec, São Paulo, Brazil). DR images were analyzed on a monitor screen using a digital ruler tool from the RVG's software system (RVG 6100, Kodak, Rochester, USA). The examiners measured the distance between the center of buccal (B) and lingual (L) root apexes of the premolars in all 120 images. The mean value of each image was compared among the three techniques by Analysis of Variance and Tukey's test. They also chose which technique, in both systems (CR and DR), showed the best diagnostic capability of root dissociation with the best distinguishable apexes with the lowest amount of distortion. The outcome variable in this case was dichotomous, good or bad quality of the radiograph. For these comparisons among the three groups, the Cochrane $\mathrm{Q}$ test was run.

\section{Results}

In order to validate the calibration made by the two examiners, all data was analyzed with the Kappa test, which showed a good level of agreement among the examiners (Kappa $=0.62$ ).

Table 2 shows the means and standard deviations of the distance between buccal and palatal apexes.

Table 1 - Experimental groups.

\begin{tabular}{|c|c|c|c|}
\hline \multirow{2}{*}{ Technique } & \multirow{2}{*}{ Angulation } & \multicolumn{2}{|c|}{ Groups } \\
\hline & & Conventional (CR) & Digital (DR) \\
\hline Parallelism & none & GPC & GPDR \\
\hline Parallelism with mesial angulation & $20^{\circ}$ horizontal mesial & GMC & GMDR \\
\hline Parallelism with mesial and vertical angulation & $25^{\circ}$ horizontal mesial / $15^{\circ}$ vertical & GMVC & GMVDR \\
\hline
\end{tabular}

Table 2 - Mean of the distance $(\mathrm{mm})$ between apexes and standard deviations.

\begin{tabular}{|c|c|c|c|}
\hline \multirow{2}{*}{ Technique } & \multicolumn{2}{|c|}{ Groups } & \multirow{2}{*}{$\begin{array}{c}\text { Comparison } \\
\text { CR X DR }\end{array}$} \\
\hline & Conventional (CR) & Digital (DR) & \\
\hline Parallelism (GP) & $1.72 \pm 1.00^{\circ}$ & $1.66 \pm 0.51^{*}$ & n.s. \\
\hline Parallelism with mesial angulation (GM) & $2.67 \pm 0.86^{b}$ & $2.26 \pm 0.69^{\dagger}$ & n.s. \\
\hline Parallelism with mesial and vertical angulation (GMV) & $2.92 \pm 0.85^{b}$ & $2.47 \pm 0.66^{+}$ & n.s. \\
\hline Comparison between techniques & $p<0.01$ & $p<0.01$ & \\
\hline
\end{tabular}

ANOVA and Tukey's test were used. Different letters or symbols show significant differences. 
The measurements of root apexes distance showed a statistically significant difference between GP and the other groups, regardless of the X-ray system according to one-way ANOVA test $(\mathrm{p}<0.01)$. Such difference, in comparison to the parallelism technique, certifies that variation of angulation can have an influence on the identification of apexes. When comparing pairs of systems (CR and DR), no significant difference was found. The GMV groups showed the greatest distances between apexes in both radiographic systems (CR and DR).

Finally, the three techniques were compared in terms of quality (good or bad) using the Cochrane Q test for matched groups (Table 3). The Parallelism technique with $25^{\circ}$ mesial and $15^{\circ}$ vertical angulations (GMV) was the most chosen method for quality root apexes dissociation $(80 \%$ in DR and $85 \%$ in CR). An increase in mesial and vertical angles improved the identification of 2 root apexes and caused less distortion of apical area, making the apex limits easy to identify. The Cochrane Q test showed significant statistical differences when comparing GMV with GP and GM groups, in both X-ray systems $(\mathrm{p}<0.05)$.

\section{Discussion}

The Parallelism Technique ${ }^{22}$ is commonly used for the diagnosis radiographs, because the images are sharp and of sufficient quality to plan an endodontic treatment. Since radiographs are two dimensional images of 3 forms, some images are usually superimposed making it difficult to distinguish the number of roots that may be found in multirooted teeth. For this reason, different radiographic techniques, specially varying horizontal angles ${ }^{9,23}$ are used to maximize the information about the studied region. This is the best way to minimize diagnostic shortcomings, during transoperative procedures and also in the post-treatment analysis.

While Walton ${ }^{9}$ concluded that a variation of $20^{\circ}$ for the horizontal angle mesially to the premolar allows the dissociation of buccal and lingual roots, Martinez-Lozano et al. ${ }^{23}$ found that $40^{\circ}$ yielded the best results. However, the present study found that an alteration in horizontal angle of $25^{\circ}$ mesially may offer a better identification of the roots and apexes without twisted or blurred image and without superimposition of other anatomic structures, like the maxillary sinus or canine root, which could occur with $40^{\circ}$. Contrary to Martinez-Lozano et al. ${ }^{23}$ who found that vertical inclination of the Xray tube did not affect the identification of roots, this study found that a variation of $15^{\circ}$ vertically, with the central beam directed towards the canine, maximized the dissociation of the root apexes in a vertical plane. Therefore, using the anterior tooth film holder instead of the posterior one, the apexes of maxillary premolars can be easily identified (Figures 1 and 2).

Table 2 shows that the mean distances using the GMV were $2.92 \mathrm{~mm}$ and $2.47 \mathrm{~mm}$ for CR and DR, larger distances than those for GM and GP. Thus, in both systems, the GMV was the most reliably utilized for the dissociation of roots. This table also indicated that CR produced higher values than the DR in all of the techniques observed. This difference may be explained by the fact that DR readings are made with a more precise digital ruler when compared with CR readings which are measured manually.

Since some authors ${ }^{17,19,24,25,26,27}$ do not consider digital image manipulation as a possible strategy,

Table 3 - Dissociation quality according to the examiner's choice (number of events and percentage).

\begin{tabular}{|c|c|c|c|}
\hline \multirow{2}{*}{ Technique } & \multicolumn{2}{|c|}{ Groups } & \multirow{2}{*}{$\begin{array}{c}\text { Comparison } \\
\text { CR X DR }\end{array}$} \\
\hline & Conventional (CR) & Digital (DR) & \\
\hline Parallelism (GP) & $0(0 \%)^{a}$ & $0(0 \%)^{*}$ & n.s. \\
\hline Parallelism with mesial angulation (GM) & $3(15 \%)^{a}$ & $4(20 \%)^{*}$ & n.s. \\
\hline Parallelism with mesial and vertical angulation (GMV) & $17(85 \%)^{b}$ & $16(80 \%)^{\dagger}$ & n.s. \\
\hline Comparison between techniques & $p<0.05$ & $p<0.05$ & \\
\hline
\end{tabular}

Cochrane $Q$ test was used. Different letters or symbols show significant differences. 

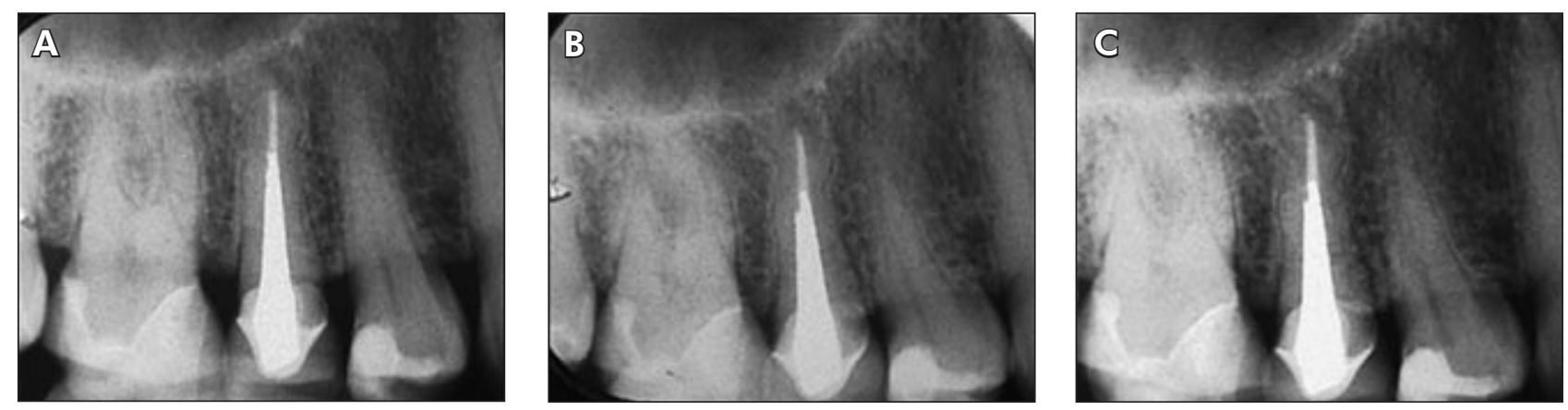

Figure 1 - Analysis of conventional radiographs using different techniques: (A) Parallelism; (B) Mesially $20^{\circ}$; (C) Mesially $25^{\circ}$ and vertical $15^{\circ}$.
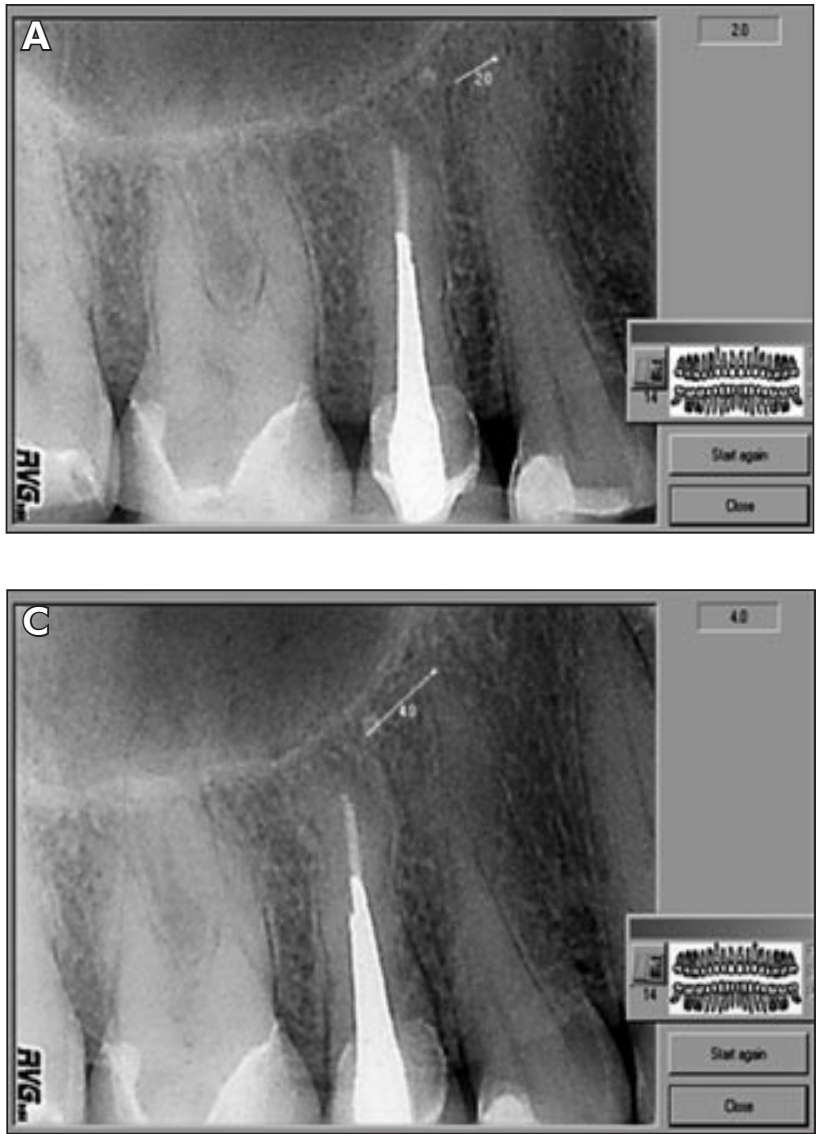

accepting only the enlargement associated to the negative - positive image inversion that allows for a better visualization of anatomic structures, ${ }^{27}$ these strategies manipulations were not used in this study. Further studies are expected to provide more information on the use of digital manipulation of images.

Results showed that the proposed technique,

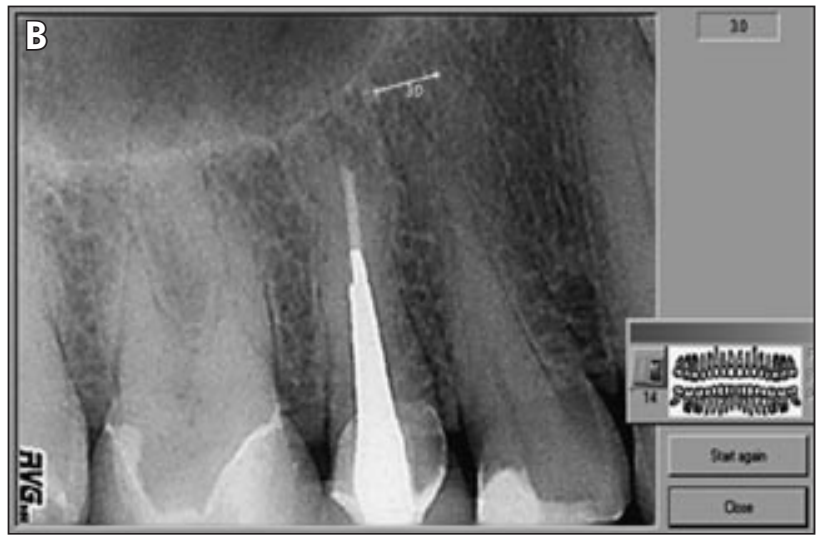

Figure 2 - Digital images

measurements with RVG 6100

software system: (A) Parallelism;

(B) Mesially $20^{\circ}$; (C) Mesially

$25^{\circ}$ and vertical $15^{\circ}$.

with mesial and vertical angle variation, using the anterior tooth film holder had improved the dissociation of buccal and lingual root canals in maxillary premolars in both radiographic systems, conventional and digital, with larger root apex distances. This technique also produced the best periapical image, with slight distortion, and easier to distinguish buccal and lingual apexes. Regarding radiographic 
systems, there were no statistically significant differences between CR and DR system.

\section{Conclusions}

According to the results, we can conclude that

\section{References}

1. Langland OE, Langlais RP. Early pioneers of oral and maxillofacial radiology. Oral Surg Oral Med Oral Pathol Oral Radiol Endod. 1995 May;80(5):496-511.

2. Wu DM, Wu YN, Guo W, Sameer S. Accuracy of direct digital radiography in the study of the root canal type. Dentomaxillofac Radiol. 2006 Apr;35(4):263-5.

3. Omer OE, Al Shalabi RM, Jennings M, Glennon J, Claffey NM. A comparison between clearing and radiographic techniques in the study of root-canal anatomy of maxillary first and second molars. Int Endod J. 2004 May;37(5):291-6.

4. Kaffe I, Gratt BM. Variations in the radiographic interpretation of the periapical dental region. J Endod. 1988 Jul;14(7):3305 .

5. Gelfand M, Sunderman EJ, Goldman M. Reliability of radiographical interpretations. J Endod. 1983 Feb;9(2):71-75.

6. Vertucci JF, Gegauff A. Root canal morphology of the first premolar. J Am Dent Assoc. 1979 Aug;99(2):194-8.

7. Kartal N, Özçelik B, Cimilli H. Root canal morphology of maxillary premolars. J Endod. 1998 Jun;24(6):417-9.

8. Green D. Double canals in single roots. Oral Surg Oral Med Oral Pathol. 1973 May;35(5):689-96.

9. Walton RE. Endodontic radiographic technics. Dent Radiogr Photogr. 1973 Mar;46(3): 51-9.

10. Ferreira RI, Haiter-Neto F, Tabchoury CPM, Paiva GAN, Bóscolo FN. Assessment of enamel demineralization using conventional, digital, and digitized radiography. Braz Oral Res. 2006 Apr-Jun;20(2):114-9.

11. Mouyen F, Benz C, Sonnabend E, Lodter JP. Presentation and physical evaluation of RadioVisioGraphy. Oral Surg Oral Med Oral Pathol. 1989 Aug 68(2):238-42.

12. Burger CL, Mork TO, Hutter JW, Nocoll B. Direct digital radiography versus conventional radiography for estimation of canal length in curved canals. J Endod. 1999 Apr;25(4):260 3.

13. Vandre RH, Pajak JC, Abdel-Nabi H, Farman TT, Farman AG. Comparison of observer performance in determining the position of endodontics files with physical measures in the evaluation of dental X-ray imaging systems. Dentomaxillofac Radiol. 2000 July;29(4):216-22.

14. Wenzel A, Grondahl HG. Direct digital radiography in the dental office. Int Dent J. 1995 Feb;45(1): 27-34.

15. Gundappa M, Ng SY, Whaites EJ. Comparison of ultrasound, digital and conventional radiography in differentiating peri- the use of anterior teeth film holder improved dissociation of buccal and lingual root apexes in both systems, CR and DR, producing sharper and clearer images to better plan the endodontic treatment.

apical area. Dentomaxillofac Radiol. 2006 Sep;35(5):32633.

16. Folk RB, Thorpe JR, Mc Clanahan SB, Johnson JD, Strother JM. Comparison of two different direct digital radiography systems for the ability to detect artificially prepared periapical lesions. J Endod. 2005 Apr;31(4):304-6.

17. Versteeg KH, Sanderink GCH, Van Ginkel FC, Van Der Stelt PF. Estimating distances on direct digital images and conventional radiographs. J Am Dent Assoc. 1997 Apr;128(4):439_ 43.

18. Westphalen VP, Gomes de Moraes I, Westphalen FH. Efficacy of conventional and digital radiographic imaging methods for diagnosis of simulated external root resorption. J Appl Oral Sci. 2004 Apr-Jun;12(2):108-12.

19. Sullivan JR, Di Fiore PM, Koerber A. Radiovisiography in detection of periapical lesions. J Endod. 2000 Jan;26(1):325.

20. Constante IGT, Davidowicz H, Barletta FB, Moura AAM. Study of the areas and thicknesses of mesiobucal root canals prepared by three endodontic techniques. Braz Oral Res. 2007 Apr-Jun;21(2):118-26.

21. Fuhrmann AW. Current practice in conventional and digital intraoral radiography: Problems and solutions. Int J Comput Dent. 2006 Jan;9:(1)61-8.

22. Fitzgerald GM. Dental roentgenography I: an investigation in adumbration or the factors that control geometric unsharpness. J Am Dent Assoc. 1947 Jan;34(1):1-20.

23. Martinez-Lozano MA, Forner-Navarro L, Sánchez-Cortés $\mathrm{JL}$. Analysis of radiologic factors in determinig premolar root canal systems. Oral Surg Oral Med Oral Pathol Oral Radiol Endod. 1999 Jun;88(6):719-22.

24. Welander U, Yoshiura K, Li G, Sallstrom P, McDavid WD. Correction for attenuation and visual response in digital radiography. Dentomaxillofac Radiol. 2002 Mar;31(2):117-25.

25. Naoum HJ, Chandler NP, Love RM. Conventional versus storage phosphor-plate digital images to visualize the root canal system contrasted with a radiopaque medium. J Endod 2003 May; 29(5):349-52.

26. Farman AG, Farman TT. A comparison of 18 different x-ray detectors currently used in dentistry. Oral Surg Oral Med Oral Pathol Oral Radiol Endod. 2005 Apr;99(4):485-9.

27. Nair MK, Nair UP. Digital and Advanced Imaging in Endodontics: A review. J Endod. 2007 Jan;33(1):1-6. 